\title{
Acquiring 'a new way of thinking about theatre...'
}

\author{
Šárka Havlíčková Kysová
}

John Lutterbie. An Introduction to Theatre, Performance and the Cognitive Science. Bloomsbury: Methuen Drama, 2020. 208 pp. ISBN 978-1-4742-5704-6

John Lutterbie is a professor at Stony Brook University in New York who in his research and teaching focuses on cognitive approaches to theatre, a broad theme on which he has authored and published several scholarly works. I recall his excellent chapter in one of the first books which began exploring this at-the-time relatively new field of study, Performance and Cognition: Theatre Studies and the Cognitive Turn (edited by Bruce McConnachie and F. Elizabeth Hart, Routledge, 2006). Lutterbie's chapter was one of the inspirations that attracted me to the study of the discipline. Lutterbie's chapter 'Neuroscience and creativity in the rehearsal process' (149-166) focuses on the cognitive approach in the area of acting: e.g. by examining the emotions and metaphorical structuring of consciousness, in different acting techniques. Five years later, Lutterbie further developed this theme in his 2011 book Toward a General Theory of Acting: Cognitive Science and Performance (Palgrave Macmillan).

In his new book, An Introduction to Theatre, Performance and the Cognitive Science (Bloomsbury), Lutterbie examines mostly 'Western' theatre, using examples from Europe and the USA. He focuses on three aspects connecting theatre and life: cognition, performance, and spectatorship. He aims at discovering 'a new way of thinking about theatre, performance, and perhaps cognitive science as well' (6). The book is clearly not intended as a purely academic treatise. Instead, Lutterbie wants to put forth a textbook that helps readers - perhaps mostly students - to actively think about the cognitive aspects of various performance experiences. The concept of the textbook is supported by many short sections featuring various tasks for students (usually intended for classroom activities). These simple tasks often challenge the reader to reflect upon their own experiences - both from everyday life and theatre.

The book is divided into six chapters preceded by an introductory section and followed by the Epilogue. Chapter 1 ('Landscapes') introduces the reader to a way of experiencing a theatrical event. The author begins his exploration of the worlds of theatre by introducing Tim Ingold's (2007) distinction between two concepts: transport and wayfaring. Instead of focussing on getting from point A to point B, a wayfarer experiences his path differently, eager to experience the journey, not just to maintain forward momentum to achieve a goal. This starting point of Lutterbie's book could also be understood as a metaphor for going through the experience of reading it. The author provides the reader with key concepts he/she needs for his or her wayfaring through the world of theatre and also for comprehending 
the message of the book itself. The author introduces theoretical conceptions such as the theatre as a dynamic system within Dynamic Systems Theory (19-23), then moves to the option of reflecting on theatre through the 4-E Theory of Cognition, through which Lutterbie is able to share comments on understanding the theatre through a complex of embodied, enacted, extended and embedded cognition (26$31)$. The concept of affordance (31-34) is then introduced, along with Conceptual Metaphor Theory and Conceptual Blending/Integration Theory (34-37). Finally, a number of lesser known theories are explored such as the concept of plasticity (40-42).

In Chapter 2, 'Culture and the Petri Dish', Lutterbie introduces the reader to several themes not always related to theatre, e.g. neuroscience, and some that have been used as theoretical and practical tools, such as anthropology. He examines various yet interconnected notions such as acting technique, neural plasticity, memory and cultural capital, among others (45-67). Chapter 3 serves as a bridge to the world of theatre and performance, carrying the wayfarer to the 'Worlds of Performance' (69-102) in a section that examines various aspects of performance space and different ways of experiencing one's surroundings. The following chapters are focused on three crucial aspects of theatre: temporality (Chapter 4, 103-127), text (Chapter 5, 129-155), and aesthetics (Chapter 6, 157-176). Lutterbie's lucid insights and comments are based on a range of numerous types of sources which enable him to employ various theoretical and methodological approaches. He builds on a phenomenological understanding of the world around us, referring mostly to Hus- serl, particularly in reflections on ways of experiencing time. Lutterbie also follows ideas rooted in other approaches, applying e.g. theories of Gilles Deleuze. Chapter Five is focused on the theatrical text and related aspects from different perspectives, starting with structuralism, briefly introducing the readers to Saussurean and Peircean semiotics, then providing an overview of Noam Chomsky's approach to language. From here Lutterbie shifts to key concepts of cognitive linguistics, including cognitive blending and metaphor. In dealing with the question of time and space, Lutterbie applies phenomenological 'inspiration' to this topic and manages to elucidate conceptions and uses of time and space in the theatre without omitting any crucial aspects and principles. In my opinion, he provides the reader with just the right amount of information to fully cover this intriguing topic. Nevertheless, in his attempt to clarify the complex questions of theatrical text, Lutterbie omits some relevant topics, such as the contributions of members of the Prague School of linguistics to theatre theory, as well as the seminal works of Erika Fischer-Lichte and Keir Elam, thus a number of significant themes relevant for any student of theatre theory are missing. This is perhaps a weak point in Lutterbie's book, a work in which any weaknesses at all are hard to find. In the course of his book the author proves his exceptional skill in introducing complex topics in a highly comprehensible way. The last chapter - Chapter 6 - focuses on aesthetics and includes the re-examination of some aesthetic categories from a cognitive perspective. For instance, Lutterbie deals with Antonin Artaud's concept of cruelty and Bertolt Brecht's defamiliarization in the broader context of the 'horizon 
of expectations' of the spectator. Lutterbie introduces the reader to selected topics on neuroaesthetics, basing his insights mostly on the findings of V. S. Ramachandran. Special attention is devoted e.g. to reorganization of perspective (164) and to the relation of temporality and aesthetics.

One of the main topics of Lutterbie's work revolves around the idea that a theatrical event or a performance should give a spectator more than he/she anticipates and push beyond the threshold in order to capture and maintain his/her attention since 'by exceeding expectations, the experience makes a lasting impression that you cannot easily shake' (176), which according to Lutterbie is the very definition of '[t]he aesthetic experience' (10). Lutterbie also considers various instances of the theatrical experience in terms of an 'act of contemplation' (176), a moment or a situation which could occur immediately or even long after the theatrical event, when the spectator begins 'to piece things together' and develops 'the understanding of the encounter' through which reflection occurs, and emotions and thoughts return (176). I agree with this characterisation of 'post-experiencing' a theatrical event and with Lutterbie's understanding of this situation as a contemplative act. On the other hand, Lutterbie in my opinion slightly underestimates the contemplative potential of theatrical event itself. I would say that in many instances a spectator doesn't ask or expect for his/her expectations to be exceeded, especially the case with seasoned aficionados of theatrical production and performance. $\mathrm{He} /$ she is not necessarily 'lazy', 'unwilling' or reluctant to allow the performance to exceed his expectations. The theatre goer might simply visit the theatre with the full intention of experiencing a contemplative act or, maybe, even to go through an expectable or comforting theatrical experience.

Lutterbie's book represents an excellent introduction to cognitive approach to theatre. The author provides his readers with a many keen insights into numerous topics directly connected as well as unexpectedly tangential to theatre studies. He includes well-elaborated tasks for students in each chapter, and he also features many instructive and well explained concrete examples. I find his strategy of applying examples repeatedly in different chapters in various yet interrelated cases very efficient and functional. Moreover, he adds an elaborate 'Further Reading' section, as well as a refreshing Epilogue. I am sure that Lutterbie's new book will considerably enhance the way we reflect upon our experiences of theatre. The work provides many highways and byways through which the wayfarer may enjoy pleasant and often stimulating journeys along the way.

\section{Bibliography}

INGOLD, Tim. 2007. Lines a Brief History. London/New York: Routledge, 2007.

LUTTERBIE, John. 2011. Toward a General Theory of Acting: Cognitive Science and Performance. New York: Palgrave Macmillan, 2011. 
